\title{
A two-step mortality model for even-aged stands of Pinus radiata D. Don in Galicia (Northwestern Spain)
}

\author{
Juan Gabriel Álvarez GonZÁLEZ ${ }^{\mathrm{a} *}$, Fernando CASTEDo DORADO ${ }^{\mathrm{b}}$, Ana Daría RuIZ GonZÁleZ ${ }^{\mathrm{a}}$, \\ Carlos Antonio LÓPEZ SÁNCHEZ ${ }^{\mathrm{a}}$, Klaus vON GADOW ${ }^{\mathrm{c}}$ \\ a Departamento de Ingeniería Agroforestal, Escuela Politécnica Superior de Lugo, Universidad de Santiago de Compostela, \\ Campus Universitario s/n, 27002, Lugo, Spain \\ b Departamento de Ingeniería Agraria, Escuela Superior y Técnica de Ingeniería Agraria, Universidad de León, \\ Avda. de Astorga s/n, 24400, Ponferrrada, Spain \\ c Institut für Waldinventur und Waldwachstum, Georg-August-Universität Göttingen, Büsgenweg 5, 37077, Göttingen, Germany
}

(Received 7 July 2003; accepted 2 September 2003)

\begin{abstract}
A two-step mortality model for even-aged Pinus radiata stands in Galicia (Northwestern Spain) is presented. The model was developed using data from two inventories of a trial network involving 130 permanent plots. The model consists of two complementary equations. The first equation is a logistic function predicting the probability of complete survival depending on stems per hectare, age and relative spacing index. The second equation estimates the reduction in the number of stems that is observed in a stand where natural mortality occurs. Fourteen equations were fitted utilising the plots where trees died over the time period analyzed. Estimates from this second model are then reduced using three different stem number projection methods: a stochastic approach, a deterministic rule-based method and another deterministic approach that compares the probability of mortality using a threshold value. The values and signs of the parameters in both equations are consistent with existing experience about natural mortality of Pinus radiata in the region of Galicia.
\end{abstract}

logistic regression / Pinus radiata / even-aged forest / mortality

Résumé - Modèle de mortalité en deux étapes pour des peuplements équiennes de Pinus radiata D. Don en Galicie (nord-ouest de l'Espagne). Il s'agit de la présentation d'un modèle de mortalité à deux étapes pour des peuplements équiennes de Pinus radiata en Galicie (au nord de l'Espagne). Le modèle a été développé à partir de données de deux inventaires de 130 échantillons permanents. Le modèle est basé sur deux équations: la première, est une fonction logistique pouvant prévoir la probabilité de survie totale en fonction du nombre d'arbres par hectare, de l'âge et de l'index d'espacement relatif. La seconde équation donne une estimation de la réduction du nombre d'arbres observée dans un peuplement où il y a mortalité naturelle. Quatorze équations ont été inclues en utilisant des parcelles où des arbres sont morts durant la période d'analyse. Les estimations tirées de ce second modèle sont ensuite réduites en utilisant trois différentes méthodes de projection du nombre d'arbres: une approche stochastique, une méthode déterminative réglementée et une autre approche déterminative qui compare la probabilité de mortalité en utilisant une méthode de seuil. Les valeurs et signes paramétriques des deux équations s'accordent avec les expériences existantes sur la mortalité naturelle du Pinus radiata de la région de Galicie.

régression logistique / Pinus radiata / peuplements équienne / mortalité

\section{INTRODUCTION}

A managed forest is a dynamic biological system that is continuously changing. Periods with undisturbed natural growth are interrupted by disturbances caused by natural hazards (e.g., fires, wind, ...) or human interference (e.g., thinning or pruning). Forest management decisions are based on information about current and future forest conditions, so it is often necessary to project the changes of the system over time. Dynamic growth and yield models are useful tools to describe forest development and hence they have been widely used in forest management because of their ability to evaluate the conse- quences of a particular management action on the future of the system providing information for decision-making [13, 29].

According to García [14], the basic elements of these types of models are: a description of the forest state at a given point in time; some transition functions to define the rate of change of the system depending on the current state of the stand; and finally some control functions to regulate the modifications of the values of the main stand variables caused by instantaneous changes of the state due to silvicultural treatments.

One of the most important transition functions of a dynamic growth and yield model is a mortality model that estimates the natural decline in number of trees caused by stand density,

* Corresponding author: algonjg@lugo.usc.es 
Table I. Summary of some stand-level variables for the first and the second inventory.

\begin{tabular}{|c|c|c|c|c|c|c|c|c|}
\hline \multirow[t]{2}{*}{ Variable } & \multicolumn{4}{|c|}{ 1st INVENTORY $($ PLOTS $=130)$} & \multicolumn{4}{|c|}{ 2nd INVENTORY $($ PLOTS $=130)$} \\
\hline & Mean & Max. & Min. & SD & Mean & Max. & Min. & SD \\
\hline Stand age (years) & 22.9 & 38.0 & 11.0 & 8.6 & 25.8 & 41.0 & 14.0 & 8.6 \\
\hline Dominant height $(\mathrm{m})$ & 19.5 & 32.7 & 5.8 & 5.3 & 21.7 & 34.1 & 10.9 & 5.2 \\
\hline Site index (m, base age 20) & 19.7 & 26.6 & 15.3 & 2.4 & 19.7 & 26.6 & 15.3 & 2.4 \\
\hline Basal area $\left(\mathrm{m}^{2} \cdot \mathrm{ha}^{-1}\right)$ & 31.5 & 59.7 & 5.3 & 10.9 & 36.4 & 70.6 & 16.2 & 10.2 \\
\hline Quadratic mean diameter $(\mathrm{cm})$ & 24.2 & 49.6 & 8.0 & 10.2 & 26.8 & 53.8 & 11.5 & 10.1 \\
\hline Number of stems $\left(\mathrm{ha}^{-1}\right)$ & 906.7 & 2048.0 & 250.0 & 502.5 & 832.9 & 1936.0 & 220.0 & 455.2 \\
\hline Relative spacing & 20.1 & 53.2 & 10.1 & 5.7 & 18.4 & 34.4 & 10.8 & 4.7 \\
\hline
\end{tabular}

droughts and other environmental factors. However, mortality remains one of the least understood components of natural processes growth.

Lee [19] distinguished two types of mortality: regular and irregular mortality. Regular mortality, or self-thinning, is due to competition for light, water and soil nutrients within a stand [28]. Irregular mortality results from random disturbances or hazards such as fire, wind, snow or insect outbreaks.

Natural tree mortality is a complex process that is neither constant in time nor in space, so it is difficult to predict or explain the factors that control it [36]. Data from permanent sample plots frequently show that a relatively large part of the plots have no occurrences of mortality even over periods of several years, e.g. $[10,12,26]$. This means that if all plots are included in model development it would probably be difficult to select an adequate set of significant variables, and statistical problems due to the binomial nature of mortality would be present. Otherwise, if only the plots where mortality has occurred are used in the model it may overestimate the mortality rate for a large-scale forestry scenario [11].

Woollons [39] suggested a way out of these problems by employing a two-step modelling method similar to one frequently applied in Decision Theory [15]. In the first step, a function predicting the probability of a plot having mortality must be developed using all sample plots (i.e. plots with and without mortality). In the second step an equation to estimate the stem number reduction must be fitted only to the sample plots with occurrence of mortality. Finally, the estimates derived from the stem number equation are modified using deterministic or stochastic approaches [25, 26, 38].

The objective of this study was to develop a two-step mortality model for even-aged stands of Pinus radiata including competition-induced mortality (regular mortality) and noncompetition-induced mortality (irregular mortality) by relating mortality to a few stand-level variables (e.g., age, density, site index, ...) that affect the natural mortality process.

\section{MATERIALS AND METHODS}

\subsection{Data}

The data in this study are from a trial network of 130 permanent plots installed in pure and even-aged Pinus radiata D. Don stands located all over Galicia (Northwestern Spain). Plots were subjectively selected to represent the range of age, stand densities and site quality in the area. The plot size ranged from $625 \mathrm{~m}^{2}(25 \times 25 \mathrm{~m})$ to $1200 \mathrm{~m}^{2}$ $(40 \times 30 \mathrm{~m})$ depending on the stand density. At least 30 trees were included in each plot.

The sample plots were established between 1995 and 1997 and remeasured after three or four years, i.e. between 1998 and 2001. This period of time is considered enough to represent the natural mortality process of a fast-growing species like radiata pine in Galicia, although irregular climatic conditions during this period may have effects on mortality rates that are balanced only during longer periods of time [10].

All the trees in each sample plot were labelled with a number. The breast height diameter was measured cross-wise. A 30-tree randomised sample and an additional sample including the dominant trees were measured for height. Descriptive variables of each tree were recorded, including mortality.

For each one of the two inventories, the following stand variables were calculated: basal area, quadratic mean diameter, average height, dominant height, age, stem number per hectare, site index and relative spacing index $\left(R S_{i}\right)$ in percent calculated for stand $i$ as follows:

$$
R S_{i}=\frac{10000 / \sqrt{N_{i}}}{H_{i}}
$$

where $N_{i}$ is the number of stems per hectare and $H_{i}$ is the dominant stand height $(\mathrm{m})$. The site indices (base age $=20$ years) were calculated using the polymorphic height model developed by Sánchez Rodríguez [33] for Pinus radiata in Galicia.

Mean, maximum and minimum values and standard deviations (SD) for the main stand variables (for the first and second inventory of the 130 sample plots) are presented in Table I. Ninety-two plots $(70.8 \%)$ showed stem death between the first and second inventory. The mortality percentage, based on the number of trees per hectare, ranged from $0.8 \%$ to $37.9 \%$, with a mean value of $11.2 \%$. The main reason for this high mortality is the lack of silvicultural operations, mainly thinning, consequently many suppressed and weak co-dominant trees died as result of the intraspecific competition [20,33].

\subsection{Model specification}

A two-step regression approach was used to model the observed natural mortality. In the first step, an equation to predict the probability of survival of all trees in the stand was fitted, and in the second step a mortality function to estimate the stem number reduction due to mortality was developed.

Natural mortality is a discrete event where only the values 0 (presence) or 1 (absence) are possible. Therefore, it would be desirable to use a function that provides estimates of probability to model mortality. Although most cumulative distributions functions will work, the logistic 
or logit function is the most widely used in mortality models for stands or individual trees $[1,10,11,16,25,26,39,40]$. The logistic model is formulated as follow:

$$
\pi=\left(\frac{1}{1+e^{-\left(b_{0}+b_{1} \cdot x_{1}+\ldots+b_{k} \cdot x_{k}\right)}}\right)^{t}
$$

where $\pi$ represents the probability of survival for all trees in a plot (i.e. mortality is given by $1-\pi$ ) over a time interval of $t$ years, $b_{k}$ are the parameters and $x_{k}$ are the explanatory variables which characterize the competitive state in the stand. Since the remeasurement intervals of the plots were irregular, it was necessary to weight the logistic function to account for time using the exponent $t$ [25]. In this equation, when the time interval increases, the survival probability decreases and gradually approaches zero.

The estimates of the parameters $\left(b_{k}\right)$ were obtained using the NLIN procedure [34] with iteratively re-weighted nonlinear regression to maximize the log likelihood function of equation (1):

$$
\begin{aligned}
l(\hat{\pi}, b)= & -\sum_{i=1}^{n_{1}} t \cdot \log \left(1+e^{-\left(b_{0}+b_{1} \cdot x_{i 1}+\ldots+b_{k} \cdot x_{i k}\right)}\right) \\
& +\sum_{j=1}^{n_{0}} \log \left[1-\left(1+e^{-\left(b_{0}+b_{1} \cdot x_{j 1}+\ldots+b_{k} \cdot x_{j k}\right)}\right)^{-t}\right]
\end{aligned}
$$

where $n_{1}$ is the number of plots without observed mortality over a period of $t$ years and $n_{0}$ is the number of plots with observed mortality at the same period of time. The weight used was the inverse of $\hat{\pi}^{t} \cdot\left(1-\hat{t}^{t}\right)$ where $\hat{t}$ represents the estimated probability of survival for all trees in a plot over a time interval of $t$ years [21, 22].

\subsection{Explanatory variable selection}

One of the most important stages in developing this kind of model is to select the best set of independent variables to explain the probability of survival. All the stand-level variables that usually are considered to quantify the competitive state in a forest stand were included as independent variables in the general logistic model: stand density, defined by live stem number per hectare in the first inventory $\left(N_{1}\right)$ and the initial basal area $\left(G_{1}\right)$; initial stand age $\left(t_{1}\right)$; site quality, characterized by initial dominant height $\left(H_{1}\right)$ and site index $(S)$; and the silvicultural practice, quantified by the relative spacing index in the first inventory $\left(R S_{1}\right)$. Also, different combinations of these variables were included.

The information obtained from applying the stepwise variable selection method was combined with an understanding of the process of mortality $[1,22]$. Accordingly, different sets of independent variables were fitted using the logistic model with iteratively re-weighted nonlinear regression.

\subsection{Algebraic difference form mortality functions}

The second step of the two-step regression approach was to develop a mortality function to estimate the stem number reduction due to mortality. Many functions have been used to model empirical mortality equations. Some of them are mathematical relationships between stem number reduction and stand variables [5, 25, 32], others are biologically based functions derived from differential equations. These biologically based functions have properties that are essential in a mortality model but are not always present in a pure mathematical model: consistency, path-invariance and asymptotic limit of stocking approaching zero as age becomes very large. Also, for even-aged stands it is reasonable to assume that ingrowth is negligible, so if age at time two is greater than age at time one, the density at time two will be less than density at time one [39].

According to Clutter et al. [8] the parameters that have the most influence in the natural decrease of stem number in a forest stand are: age $(t)$, current number of stems $(N)$, and site quality represented by the site index value $(S)$. The effect of the age in the differential equations can be expressed in different ways to obtain different mortality models, even though most of them derive from the following three differential equations:

$$
\begin{aligned}
& \frac{1}{N} \cdot \frac{\Delta N}{\Delta t}=\alpha \cdot N^{\beta} \cdot f(S) \cdot t^{\delta} \\
& \frac{1}{N} \cdot \frac{\Delta N}{\Delta t}=\alpha \cdot N^{\beta} \cdot\left[f(S)+\frac{\delta}{t}\right] \\
& \frac{1}{N} \cdot \frac{\Delta N}{\Delta t}=\alpha \cdot N^{\beta} \cdot f(S) \cdot \delta^{t}
\end{aligned}
$$

where $\alpha, \beta$ and $\delta$ are parameters that regulate the mortality rate and $f(S)$ is a function of site index. Different functions have been used to take into account the effect of site index in modelling natural mortality e.g. [2, 31], but all of them can be included in the general form $f(S)=c_{0}+c_{1} \cdot S^{c_{2}}$ that has been employed in all the solutions of equations (3) to (5).

The differential equation (3) implies that the relative rate of change in the number of stems is proportional to a power function of age. Integration of equation (3) with the initial condition that $\delta \neq-1$ gives the following two algebraic difference form models depending on the value of $\beta$ :

$$
\begin{gathered}
\beta \neq 0 \quad N_{2}=\left[N_{1}^{b_{1}}+f(S) \cdot\left(t_{2}{ }^{b_{2}}-t_{1}{ }^{b_{2}}\right)\right]^{\frac{1}{b_{1}}} \\
\text { with } b_{1}=-\beta \text { and } b_{2}=\delta+1 \\
\beta=0 \quad N_{2}=N_{1} \cdot e^{f(S) \cdot\left(t_{2}{ }^{b_{1}}-t_{1}{ }^{b_{1}}\right)} \quad \text { with } b_{1}=\delta+1 .
\end{gathered}
$$

Mortality models similar to equation (6) were used by Clutter and Jones [7], Pienaar et al. [31] and Woollons [39], whereas the mortality functions of Tomé et al. [35] and Pienaar and Shiver [30] are similar to equation (7). Among these, only Pienaar's model includes site index as an independent variable. The mathematical expressions of these models are shown in Table II.

The differential equation (4) implies that the relative rate of change in the number of stems is proportional to a hyperbolic function of age. Integration of equation (4) gives the following two algebraic difference form models depending on the value of $\beta$ :

$$
\begin{array}{r}
\beta \neq 0 \quad N_{2}=\left[N_{1}^{b_{1}}+f(S) \cdot\left(t_{2}-t_{1}\right)+\ln \left(\frac{t_{2}}{t_{1}}\right)^{b_{2}}\right] \frac{1}{b_{1}} \\
\text { with } b_{1}=-\beta \text { and } b_{2}=-\alpha \cdot \beta \cdot \delta
\end{array}
$$

$$
\beta=0 \quad N_{2}=N_{1} \cdot\left(\frac{t_{2}}{t_{1}}\right)^{b_{1}} \cdot e^{f(S) \cdot\left(t_{2}-t_{1}\right)} \quad \text { with } b_{1}=\alpha \cdot \delta
$$

Similar models to equation (9) were used by Bailey et al. [2] and Zunino and Ferrando [41]. Only Bailey's model includes site index as 
Table II. Mathematical expressions of some mortality models derived from differential equations (3) to (5).

\begin{tabular}{|c|c|c|}
\hline Equation & Initial conditions & Expression \\
\hline Clutter and Jones [7] & $\begin{aligned} \beta & \neq 0 \\
f(S) & =c_{0}\end{aligned}$ & $N_{2}=\left[N_{1}^{b_{1}}+c_{0} \cdot\left(t_{2}^{b_{2}}-t_{1}^{b_{2}}\right)\right]^{\frac{1}{b_{1}}}$ \\
\hline Pienaar et al. [31] & $\begin{array}{c}\beta \neq 0 \\
f(S) \stackrel{c_{1} \cdot S^{-1}}{ }\end{array}$ & $N_{2}=\left[N_{1}^{b_{1}}+c_{1} \cdot S^{-1} \cdot\left[\left(\frac{t_{2}}{10}\right)^{b_{2}}-\left(\frac{t_{1}}{10}\right)^{b_{2}}\right]\right]^{\frac{1}{b_{1}}}$ \\
\hline Woollons [39] & $\begin{array}{c}\beta=0.5 \\
f(S)=c_{0}\end{array}$ & $N_{2}=\left[N_{1}^{-0.5}+c_{0} \cdot\left[\left(\frac{t_{2}}{100}\right)^{2}-\left(\frac{t_{1}}{100}\right)^{2}\right]\right]^{-2}$ \\
\hline Pienaar and Shiver [30] & $\begin{array}{c}\beta=0 \\
f(S)=c_{0}\end{array}$ & $N_{2}=N_{1} \cdot e^{c_{0} \cdot\left(t_{2}^{b_{1}}-t_{1}^{b_{1}}\right)}$ \\
\hline Tomé et al. [35] & $\begin{array}{c}\beta=0 \\
f(S)=c_{0}\end{array}$ & $N_{2}=N_{1} \cdot e^{c_{0} \cdot\left(t_{2}-t_{1}\right)}$ \\
\hline Bailey et al. [2] & $\begin{array}{c}\beta=0 \\
f(S)=c_{0}+c_{1} \cdot S\end{array}$ & $N_{2}=N_{1} \cdot\left(\frac{t_{2}}{t_{1}}\right)^{b_{1}} \cdot e^{\left(c_{0}+c_{1} \cdot S\right) \cdot\left(t_{2}-t_{1}\right)}$ \\
\hline $\begin{array}{l}\text { Zunino and Ferrando } \\
\text { [41] }\end{array}$ & $\begin{array}{c}\beta=0 \\
f(S)=c_{0}\end{array}$ & $N_{2}=N_{1} \cdot\left(\frac{t_{2}}{t_{1}}\right)^{b_{1}} \cdot e^{c_{0} \cdot\left(t_{2}-t_{1}\right)}$ \\
\hline Da Silva (cited in [36]) & $\begin{array}{c}\beta=0 \\
f(S)=c_{0}\end{array}$ & $N_{2}=N_{1} \cdot e^{c_{0} \cdot\left(b_{1}^{t_{2}}-b_{1}^{t_{1}}\right)}$ \\
\hline
\end{tabular}

an independent variable. The mathematical expressions for these two mortality models are shown in Table II.

The differential equation (5) implies that the relative rate of change in the number of stems is proportional to an exponential function of age. A particular case of this equation is obtained when $\delta=e$. Integration of equation (5) with the initial condition that $\delta>1$ gives the following two algebraic difference form models depending on the value of $\beta$ :

$$
\beta \neq 0 \quad N_{2}=\left[N_{1}^{b_{1}}+f(S) \cdot\left(b_{2}{ }^{t_{2}}-b_{2}{ }^{t_{1}}\right)\right]^{\frac{1}{b_{1}}}
$$$$
\text { with } b_{1}=-\beta \text { and } b_{2}=\delta
$$

$\beta=0 \quad N_{2}=N_{1} \cdot e^{f(S) \cdot\left(b_{1}{ }^{t_{2}}-b_{1}{ }^{t_{1}}\right)} \quad$ with $b_{1}=\delta$.

A model derived from equation (11) was used by Da Silva (cited in van Laar and Akça [36]) as mortality function, but site index was not included as an independent variable (Tab. II).

The functions included in Table II and the equations (6) to (11) were fitted to data from 92 plots where natural mortality had occurred. The estimates of the parameters in these 14 models were obtained by ordinary least squares using the Gauss-Newton iterative procedure [17].

\subsection{Number of trees projection}

The estimated number of live trees at time $t_{2}$ can be calculated by stochastic or deterministic approaches [26]. The stochastic rule compares the predicted survival rate with a uniform random number in the interval $(0,1)$. If the random number exceeds the estimate survival rate, the stem number at age $t_{2}$ is determined using the algebraic difference form mortality function, otherwise natural mortality does not occur and the stem number at age $t_{2}$ is equal to the initial stem number. Belcher et al. [4] suggest that the stochastic method should not be used for projections exceeding 30 years because the estimates may be inconsistent. However, this problem does not arise in the case of Pinus radiata which is grown on relatively short rotations in Galicia.

The most common deterministic approach is based on Decision Theory where the predicted number of trees at the end of the time interval of $t$ years $\left(N_{\text {pred } 2}\right)$ is expressed as $[15,39]$ :

$$
N_{\text {pred } 2}=N_{2}+\pi \cdot\left(N_{1}-N_{2}\right)
$$

where $\pi$ represents the estimated probability of survival for all trees in a plot over a time interval of $t$ years, $N_{2}$ is the number of trees estimated by an algebraic difference form mortality function and $N_{1}$ is the number of trees at the start of the period.

A second deterministic approach for simulating stand mortality involves a threshold [26]. If the estimated survival rate is less than the threshold, then natural mortality occurs and the stem number at age $t_{2}$ is determined using the algebraic difference form mortality function, 
otherwise it is equal to the initial stem number. The most logical choice of a threshold is the average observed survival rate which, in this case is equal to $0.292 \%$.

\subsection{Model evaluation and validation}

The significance of the parameters of the logistic model was tested by $z=b / A S E$, where $b$ is the parameter estimate and ASE is the asymptotic standard error [11]. To select the best set of explanatory variables, the models were compared using the value of the generalization of the coefficient of determination $\left(\widetilde{R}^{2}\right)$ proposed by Cox and Snell [9] and modified by Nagelkerke [27] and the Hosmer-Lemeshow goodnessof-fit statistic $\left(\chi_{H L}^{2}\right)$. These statistics are written:

$$
\tilde{R}^{2}=\frac{R^{2}}{R_{\max }^{2}}=\frac{1-\left[\frac{L(0)}{L(\hat{\beta})}\right]^{2 / n}}{1-L(0)^{2 / n}} \quad \chi_{H L}^{2}=\sum_{i=1}^{g} \frac{\left(O_{i}-n_{i} \bar{\pi}_{i}\right)^{2}}{n_{i} \bar{\pi}_{i}\left(1-\bar{\pi}_{i}\right)}
$$

where $L(0)$ is the likelihood of the intercept-only model; $L(\hat{\beta})$ is the likelihood of the specified model; $n$ is the sample size; $g$ is the number of groups used to calculate the Pearson chi-square statistic from the $2 \times g$ table of observed and expected frequencies, in this case $g=10$ [18]; $n_{i}$ is the total frequency of observations in the $i$ th group, $O_{i}$ is the total frequency of event outcomes in the $i$ th group, and $\bar{\pi}_{i}$ is the average estimated probability of an event outcomes for the $i$ th group.

The comparison of the estimates of the 14 mortality models fitted by ordinary least-squares was based on graphic and numeric analysis of the residuals $\left(E_{i}\right)$. Four statistical criteria were examined: bias $(\bar{E})$, which tests the systematic deviation of the model from the observations; root mean square error ( $R M S E)$, which analyses the accuracy of the estimates; the adjusted coefficient of determination $\left(R^{2}{ }_{a d j}\right)$, which shows the proportion of the total variance that is explained by the model, adjusted for the number of model parameters and the number of observations; Akaike's information criterion differences (AICd), which is an index to select the best model based on minimizing the Kullback-Liebler distance [6]. These expressions may be summarized as follows:

Bias

$$
\bar{E}=\frac{\sum_{i=1}^{n}\left(Y_{i}-\hat{Y}_{i}\right)}{n}
$$

Root mean square error

$$
R M S E=\sqrt{\frac{\sum_{i=1}^{n}\left(Y_{i}-\hat{Y}_{i}\right)^{2}}{n-p}}
$$

Adjusted coefficient of determination

$$
R_{\mathrm{adj}}^{2}=1-\frac{(n-1) \cdot \sum_{i=1}^{n}\left(Y_{i}-\hat{Y}_{i}\right)^{2}}{(n-p) \cdot \sum_{i=1}^{n}\left(Y_{i}-\bar{Y}\right)^{2}}
$$

$\begin{aligned} & \text { Akaike's information } \\ & \text { criterion differences }\end{aligned} \quad A I C d=n \cdot \ln \hat{\sigma}^{2}+2 \cdot K-\min \left(n \cdot \ln \hat{\sigma}^{2}+2 \cdot K\right)$ where $Y_{i}, \hat{Y}_{i}$ and $\bar{Y}_{i}$ are the measured, predicted and average values of the dependent variable, respectively; $n$ is the total number of observations used to fit the model; $p$ is the number of model parameters; $k=$ $p+1$, and $\hat{\sigma}^{2}$ is the estimator of the error variance of the model which value is obtained as follow:

$$
\hat{\sigma}^{2}=\frac{\sum_{i=1}^{n}\left(Y_{i}-\hat{Y}_{i}\right)^{2}}{n} .
$$

The cross-validation of each model was based on the analysis of the bias, the root mean square error of the estimates and Akaike's information criterion differences, using the residual of each plot as obtained by refitting the model without this plot.

\section{RESULTS AND DISCUSSION}

The best set of explanatory variables obtained for the logistic model (1) is shown in Table III. The percentage of concordant pairs was of $73.7 \%$, the generalization of the coefficient of determination $\left(\widetilde{R}^{2}\right)$ obtained using the modification proposed by Nagelkerke [27] was 0.82 and the chi-square values and associated probability of Homer and Lemeshow Goodness-offit test $\left(\chi_{H L}^{2}\right)$ were 8.5653 and 0.3803 , respectively.

The probability of survival of all the trees in a stand $(\pi)$ and the probability of stand mortality $(1-\pi)$ can be calculated using the following equation:

$$
\pi=\left(\frac{1}{1+e^{-\left(-1.464-0.000037 \cdot N_{1} \cdot t_{1}+0.130 \cdot R S_{1}\right)}}\right)^{t}
$$

The product of the number of trees and age $\left(N_{1} \cdot t_{1}\right)$, and the relative spacing index $\left(R S_{1}\right)$ at the beginning of the period were found to be highly significant in predicting survival of all trees in the stand. The probability of survival decreases when the stand age or stand density increase and it increases when the value of the relative spacing index increases (e.g., with intensive thinnings). The influence of these variables was shown in other stand or tree mortality models e.g. [3, 23, 39, 40]. These results are consistent with the dynamic process of the intra-specific competition and the natural mortality of even-aged stands $[8,13,36,37]$.

The use of the time interval as an exponent in the logistic model implies that mortality in a particular year is not influenced by the mortality in previous years. This is reasonable for irregular mortality, but probably not for forest conditions with a high density. However, this possible violation of the statistical assumptions of equation (1) is not a problem when it is applied [11].

Figure 1 shows predicted and observed occurrences of mortality (100 - percent survival) plotted against number of trees, age, relative spacing index and site index. In general, survival was well predicted by the explanatory variables.

Tables IV, V and VI show the parameters estimates for each one of the 14 equations and the statistics to compare and validate them. Only the 92 sample plots where mortality occurred were used to fit these equations. 

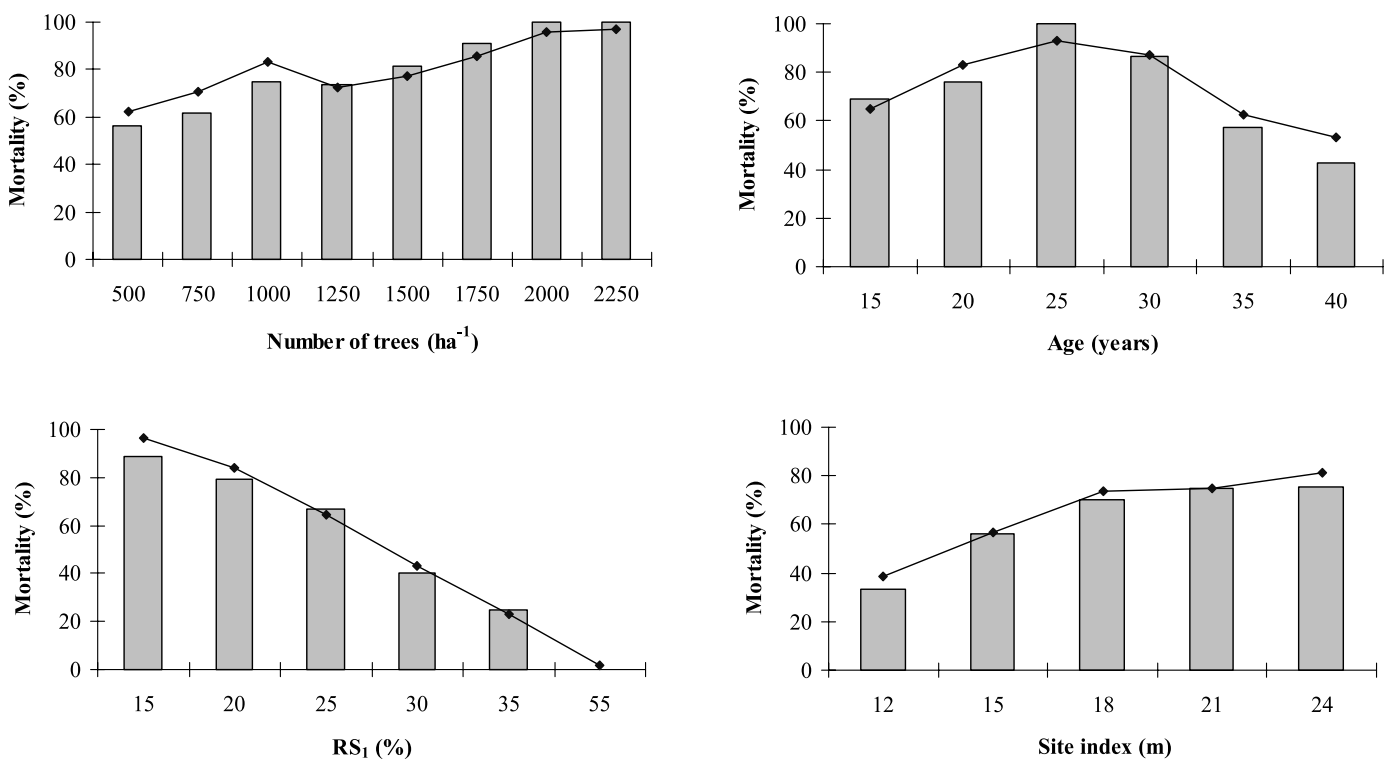

Figure 1. Predicted (Eq. (13), line) and observed (bar) occurrences of mortality over density, age, relative spacing index $\left(R S_{1}\right)$ and site index.

Table III. Estimated parameters and standard errors for occurrence of survival (Eq. (1)).

\begin{tabular}{lcc}
\hline Explanatory variable & Parameter estimate & Asymptotic standard error \\
\hline Intercept & $-1.463736 * * *$ & 0.3662 \\
$N_{1} \cdot t_{1}\left(\mathrm{ha}^{-1} \cdot\right.$ years $)$ & $-3.72 \mathrm{E}-5 * * *$ & $6.42 \mathrm{E}-6$ \\
$R S_{1}(\%)$ & $0.130140 * * *$ & 0.0293 \\
\hline
\end{tabular}

$N_{1}$ : number of trees; $t_{1}$ : age; $R S_{1}$ : relative spacing index. $* * * p<0.001$.

Analysing the results for each of the three differential equations separately, it can be observed that, in general, the equations with a bigger bias and a lower precision are those which have the initial condition $\beta=0$. These results seem to indicate that the relative rate of change in the number of stems $(\Delta N / N \cdot \Delta t)$ is directly proportional to the initial stand density, because the values of estimated $\beta$ parameter in the rest of the equations are always positive.

For equations (6) to (11) the best results were obtained when the values of $c_{0}$ and $c_{2}$ were fixed at 0 and 1 respectively, i.e. when the function of site index is a straight line without intercept. When these parameter were not fixed, the root mean square error decreased, but the Akaike's information criterion increased, because two additional parameters were included.

The inclusion of site index as explanatory variable slightly improves the estimates in all equations, except for Pienaar's equation [31] in which the relation between the relative rate of change in the number of stems $(\Delta N / N \cdot \Delta t)$ and site index is inversely proportional $\left(f(S)=S^{-1}\right)$. In the other equations in which site index is included, an increase in its value implies an increase in the stand mortality. These results are consistent with the empirical evidence that, in plantations, density-dependent mortality expresses itself earlier on better sites, and, if mortality is expressed as a function of age, it appears that mortality increases with increasing site productivity [37].

In general, using the same initial conditions, the equations with the worst results are those derived from differential equation (4). The equations obtained from differential equations (3) and (5) show very similar results. However, those in which the relative rate of change in the number of stems is proportional to an exponential function of age (differential Eq. (5)) show the more accurate estimates. Within this group, the equation with the best fit and cross-validation statistics is equation (10). Therefore, the proposed equation for estimating the reduction of the stem number between two ages $\left(t_{1}\right.$ and $\left.t_{2}\right)$ in the evenaged stands of Pinus radiata in Galicia is:

$N_{2}=\left(N_{1}^{-1.0206}+0.00000127 \cdot S \cdot\left[1.1039^{t_{2}}-1.1039^{t_{1}}\right]\right)^{\frac{-1}{1.0206}} \cdot$

The observed stem numbers at age $t_{2}$ for all 130 sample plots were compared with the estimated values obtained with equations (13) and (14) using the stochastic and the two deterministic approaches of stem number projections. In Figure 2 the observed values are plotted against the estimated values for the stochastic method 
Table IV. Parameter estimates and statistics to compare and validate the models derived from differential equation (3) with different initial conditions. (* The best results were obtained when this parameter was fixed with this value.)

\begin{tabular}{|c|c|c|c|c|c|c|c|c|c|c|}
\hline \multirow{2}{*}{ Model } & \multirow{2}{*}{ Initial conditions } & \multirow{2}{*}{ Par. } & \multirow{2}{*}{ Value } & \multicolumn{4}{|c|}{ Fit } & \multicolumn{3}{|c|}{ Cross-validation } \\
\hline & & & & $R^{2}{ }_{a d j}$ & $\bar{E}$ & RMSE & $A I C d$ & $\bar{E}$ & RMSE & AICd \\
\hline \multirow{5}{*}{ Equation (6) } & \multirow{5}{*}{$\begin{array}{c}\beta=-b_{1} \\
f(S)=c_{0}+c_{1} \cdot S^{\mathrm{c} 2}\end{array}$} & $b_{1}$ & -0.8522 & \multirow{5}{*}{0.9689} & \multirow{5}{*}{0.2599} & \multirow{5}{*}{83.48} & \multirow{5}{*}{0.4} & \multirow{5}{*}{-0.0252} & \multirow{5}{*}{87.87} & \multirow{5}{*}{0.5} \\
\hline & & $b_{2}$ & 3.0374 & & & & & & & \\
\hline & & $c_{0}$ & $0 *$ & & & & & & & \\
\hline & & $c_{1}$ & $3.361 \mathrm{E}-9$ & & & & & & & \\
\hline & & $c_{2}$ & $1 *$ & & & & & & & \\
\hline \multirow{3}{*}{ Clutter and Jones [7] } & \multirow{3}{*}{$\begin{array}{c}\beta=-b_{1} \\
f(S)=c_{0}\end{array}$} & $b_{1}$ & -0.7251 & \multirow{3}{*}{0.9663} & \multirow{3}{*}{0.1421} & \multirow{3}{*}{86.77} & \multirow{3}{*}{7.4} & \multirow{3}{*}{-0.0188} & \multirow{3}{*}{91.81} & \multirow{3}{*}{8.8} \\
\hline & & $b_{2}$ & 2.6668 & & & & & & & \\
\hline & & $c_{0}$ & $4.643 \mathrm{E}-7$ & & & & & & & \\
\hline \multirow{3}{*}{ Pienaar et al. [31] } & \multirow{3}{*}{$\begin{aligned} \beta & =-b_{1} \\
f(S) & =c_{1} \cdot S^{-1}\end{aligned}$} & $b_{1}$ & -0.6713 & \multirow{3}{*}{0.9606} & \multirow{3}{*}{-4.845} & \multirow{3}{*}{93.90} & \multirow{3}{*}{22.0} & \multirow{3}{*}{-4.7391} & \multirow{3}{*}{99.78} & \multirow{3}{*}{24.0} \\
\hline & & $b_{2}$ & 2.3501 & & & & & & & \\
\hline & & $c_{1}$ & 0.0074 & & & & & & & \\
\hline Woollons [39] & $\begin{array}{c}\beta=0.5 \\
f(S)=c_{0}\end{array}$ & $c_{0}$ & 0.1551 & 0.9653 & 1.1278 & 87.17 & 6.3 & 1.1142 & 88.93 & 0.9 \\
\hline & & $b_{1}$ & 2.0332 & & & & & & & \\
\hline & & $c_{0}$ & $0 *$ & & & & & & & \\
\hline Equation (7) & $f(S)=c_{0}+c_{1} \cdot S^{\mathrm{c} 2}$ & $c_{1}$ & $-4.978 \mathrm{E}-5$ & 0.9648 & 9.1409 & 88.30 & 9.7 & 8.9979 & 91.51 & 7.2 \\
\hline & & $c_{2}$ & $1 *$ & & & & & & & \\
\hline Pienaar and Shiver [30] & $\beta=0$ & $b_{1}$ & 1.8441 & & & & 13.2 & 8.2239 & & \\
\hline Pienaar and sniver [30] & $f(S)=c_{0}$ & $c_{0}$ & -0.00186 & 0.9634 & $8.3 / 01$ & 90.01 & 13.2 & 8.2239 & 93.17 & 10.5 \\
\hline Tomé et al. [35] & $\begin{array}{c}\beta=0 \\
f(S)=c_{0}\end{array}$ & $c_{0}$ & -0.0401 & 0.9595 & 0.1220 & 94.11 & 20.4 & 0.1196 & 95.86 & 14.7 \\
\hline
\end{tabular}

Table V. Parameter estimates and statistics to compare and validate the models derived from differential equation (4) with different initial conditions. (* The best results were obtained when this parameter was fixed with this value.)

\begin{tabular}{|c|c|c|c|c|c|c|c|c|c|c|}
\hline \multirow[t]{2}{*}{ Model } & \multirow[t]{2}{*}{ Initial conditions } & \multirow[t]{2}{*}{ Par. } & \multirow[t]{2}{*}{ Value } & \multicolumn{4}{|c|}{ Fit } & \multicolumn{3}{|c|}{ Cross-validation } \\
\hline & & & & $R_{a d j}^{2}$ & $\bar{E}$ & $R M S E$ & $\overline{A I C d}$ & $\bar{E}$ & $R M S E$ & $A I C d$ \\
\hline \multirow{5}{*}{ Equation (8) } & \multirow{5}{*}{$\begin{array}{c}\beta=-b_{1} \\
f(S)=c_{0}+c_{1} \cdot S^{\mathrm{c} 2}\end{array}$} & $b_{1}$ & -0.3585 & \multirow{5}{*}{0.9650} & \multirow{5}{*}{-3.3097} & \multirow{5}{*}{88.51} & \multirow{5}{*}{11.1} & \multirow{5}{*}{-3.4437} & \multirow{5}{*}{92.61} & \multirow{5}{*}{10.4} \\
\hline & & $b_{2}$ & -0.0288 & & & & & & & \\
\hline & & $c_{0}$ & $0 *$ & & & & & & & \\
\hline & & $c_{1}$ & $1.386 \mathrm{E}-4$ & & & & & & & \\
\hline & & $c_{2}$ & $1 *$ & & & & & & & \\
\hline \multirow{4}{*}{ Equation (9) } & \multirow{4}{*}{$\begin{array}{c}\beta=0 \\
f(S)=c_{0}+c_{1} \cdot S^{\mathrm{c} 2}\end{array}$} & $b_{1}$ & 0.8402 & \multirow{4}{*}{0.9639} & \multirow{4}{*}{2.9224} & \multirow{4}{*}{89.42} & \multirow{4}{*}{12} & \multirow{4}{*}{2.8408} & \multirow{4}{*}{92.62} & \multirow{4}{*}{9.4} \\
\hline & & $c_{0}$ & $0 *$ & & & & & & & \\
\hline & & $c_{1}$ & $-4.429 \mathrm{E}-3$ & & & & & & & \\
\hline & & $c_{2}$ & $1 *$ & & & & & & & \\
\hline \multirow{3}{*}{ Bailey et al. [2] } & \multirow{3}{*}{$\begin{array}{c}\beta=0 \\
f(S)=c_{0}+c_{1} \cdot S\end{array}$} & $b_{1}$ & 0.9834 & \multirow{3}{*}{0.9641} & \multirow{3}{*}{8.9219} & \multirow{3}{*}{89.18} & \multirow{3}{*}{11.5} & \multirow{3}{*}{7.3881} & \multirow{3}{*}{92.57} & \multirow{3}{*}{10.3} \\
\hline & & $c_{0}$ & -0.0457 & & & & & & & \\
\hline & & $c_{1}$ & -0.00258 & & & & & & & \\
\hline \multirow{2}{*}{ Zunino and Ferrando [41] } & $\beta=0$ & $b_{1}$ & 0.7305 & \multirow[b]{2}{*}{0.9637} & \multirow[b]{2}{*}{7.0004} & & & & & \\
\hline & $f(S)=c_{0}$ & $c_{0}$ & -0.0822 & & & 89.66 & 12.5 & 6.7801 & 93.55 & 11.3 \\
\hline
\end{tabular}




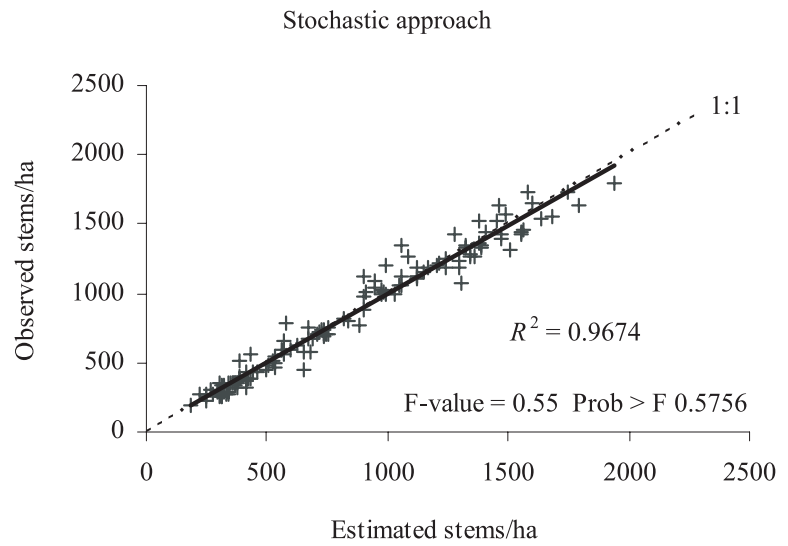

Decision theory deterministic approach
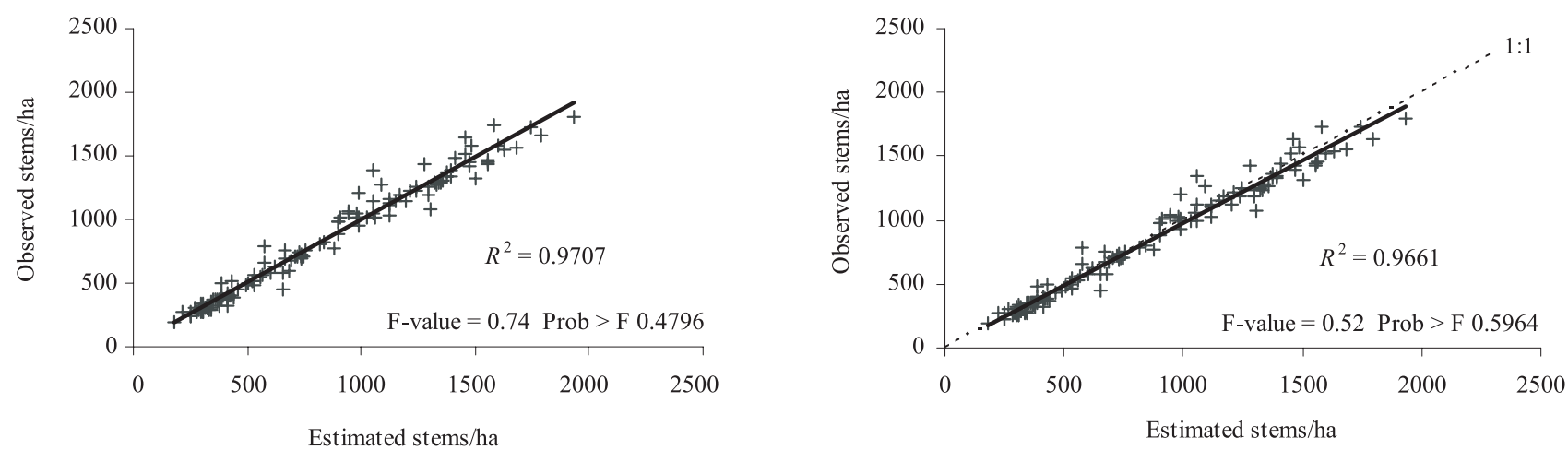

Figure 2. Plots of observed against estimated number of stems for the three projection methods. The solid line represents the linear model fitted to the scatter plot of data and the dotted line is the diagonal. $R^{2}$ is the determination coefficient of the linear model and the F-value and the probability associated are of the simultaneous test for intercept $=0$ and slope $=1$.

Table VI. Parameter estimates and statistics to compare and validate the models derived from differential equation (5) with different initial conditions. (* The best results were obtained when this parameter was fixed with this value.)

\begin{tabular}{|c|c|c|c|c|c|c|c|c|c|c|}
\hline \multirow[t]{2}{*}{ Model } & \multirow[t]{2}{*}{ Initial conditions } & \multirow[t]{2}{*}{ Par. } & \multirow[t]{2}{*}{ Value } & \multicolumn{4}{|c|}{ Fit } & \multicolumn{3}{|c|}{ Cross-validation } \\
\hline & & & & $R_{a d j}^{2}$ & $\bar{E}$ & $R M S E$ & AICd & $\bar{E}$ & $R M S E$ & AICd \\
\hline \multirow{4}{*}{ Equation (10) } & \multirow{4}{*}{$\begin{array}{c}\beta \neq 0 \\
f(S)=c_{0}+c_{1} \cdot S^{\mathrm{c} 2}\end{array}$} & $b_{1}$ & -1.0206 & \multirow{4}{*}{0.9689} & \multirow{4}{*}{-0.3174} & \multirow{4}{*}{83.33} & \multirow{4}{*}{0} & \multirow{4}{*}{-0.6218} & \multirow{4}{*}{87.56} & \multirow{4}{*}{0} \\
\hline & & $\begin{array}{l}b_{2} \\
c_{0}\end{array}$ & $\begin{array}{c}1.1039 \\
0 *\end{array}$ & & & & & & & \\
\hline & & $c_{1}$ & $2.127 \mathrm{E}-6$ & & & & & & & \\
\hline & & $c_{2}$ & $1 *$ & & & & & & & \\
\hline \multirow{3}{*}{ Equation (11) } & \multirow{3}{*}{$\begin{array}{c}\beta=0 \\
f(S)=c_{0}+c_{1} \cdot S^{\mathrm{c} 2}\end{array}$} & $b_{1}$ & 1.0449 & \multirow{3}{*}{0.9659} & \multirow{3}{*}{7.8261} & \multirow{3}{*}{87.39} & \multirow{3}{*}{8.8} & \multirow{3}{*}{8.8040} & \multirow{3}{*}{92.25} & \multirow{3}{*}{8.7} \\
\hline & & $\begin{array}{l}c_{0} \\
c_{1}\end{array}$ & $\begin{array}{c}0 * \\
-0.0202\end{array}$ & & & & & & & \\
\hline & & $c_{2}$ & $1 *$ & & & & & & & \\
\hline $\begin{array}{l}\text { Da Silva } \\
\text { (cited in [36]) }\end{array}$ & $\begin{array}{c}\beta=0 \\
f(S)=c_{0}\end{array}$ & $b_{1}$ & $\begin{array}{r}1.0367 \\
-0.5589\end{array}$ & 0.9630 & 8.3820 & 90.54 & 14.3 & 12.5541 & 96.27 & 89.6 \\
\hline
\end{tabular}


(using a uniform random number), the deterministic method based on Decision Theory (Eq. (12)) and the deterministic method based on the use of the threshold of 0.708 (observed mortality rate). A linear model was fitted for each scatter plot and the coefficient of determination and the result of the simultaneous test for intercept $=0$ and slope $=1$ are shown in Figure 2.

There are not significant differences between the three methods. The values of the coefficient of determination are very similar and the results of the simultaneous F-test show that there are no systematic over or underestimates in any model. Similar results were obtained by Weber et al. [38] in an individual tree mortality model using the stochastic and the decision theory based deterministic approaches.

\section{CONCLUSIONS}

A two-step mortality model for radiata pine in Galicia was developed. The probability of survival at the first step is mainly influenced by the interaction of number of tress $\times$ age. Estimates of mortality rate are increasing with higher stocking levels and higher stand age. At the second step, the best results were obtained when the function for estimating stem number reduction includes the site index as explanatory variable. Mortality functions derived from differential equations, where the relative rate of change in the stem number $(\Delta N / N \cdot \Delta t)$ is directly proportional to the initial stand density, showed the highest accuracy.

Significant differences in the statistics among the three different methods proposed for projecting the number of trees were not found. Thus, for all practical purposes either method will estimate average values with the same accuracy at the forest level.

However, according to Woollons [39], the use of a stand mortality model for a large-scale forestry scenario implies that the stochastic nature of stem death must be emphasised to avoid "smoothing" the survival by using a deterministic approach. Therefore, the use of the stochastic approach is recommended.

Acknowledgements: The research reported in this paper was supported by the project AGL2001-3871-C02-01 of the Plan Nacional de Investigación Científica, Desarrollo e Innovación Tecnológica 2000-2003 (Ministerio de Ciencia y Tecnología). We are also grateful to two anonymous referees for their valuable comments on the manuscript.

\section{REFERENCES}

[1] Avila O.B., Burkhart H.E., Modelling survival of loblolly pine trees in thinned and unthinned plantations, Can. J. For. Res. 22 (1992) 1878-1882.

[2] Bailey R.L., Borders B.E., Ware K.D., Jones E.P., A compatible model for slash pine plantation survival to density, age, site index and type and intensity of thinning, For. Sci. 31 (1985) 180-189.

[3] Barclay H.J., Layton C.R., Growth and mortality in managed Douglas-fir: relation to a competition index, For. Ecol. Manage. 36 (1990) 187-204.
[4] Belcher D.W., Holdaway M.R., Brand G.J., A description of STEMS The stand and tree evaluation and modelling system, Gen. Tech. Rep. NC-79, USDA Forest Service, North Central Forest Experimental Station, 1982.

[5] Brendenkamp B.V., The estimation of mortality in stands of Eucalyptus grandis, Festschr. Fac. For. Stellenbosch (1988) 1-15.

[6] Burnham K.P., Anderson D.R., Model selection and inference. A practical information-theoretic approach, Springler-Verlag, New York, 1998.

[7] Clutter J.L., Jones E.P., Prediction of growth after thinning in oldfield slash pine plantations, USDA For. Serv. Pap. SE-217, 1980.

[8] Clutter J.L., Fortson J.C., Pienaar L.V., Brister G.H., Bailey R.L., Timber management. A quantitative approach, John Wiley \& Sons, New York, 1983.

[9] Cox D.R., Snell E.J., Analysis of binary data, 2nd ed., London, Chapman and Hall, 1989.

[10] Eid T., Tuhus E., Models for individual tree mortality in Norway, For. Ecol. Manage. 154 (2001) 69-84.

[11] Eid T., Øyen B.H., Models for prediction of mortality in even-aged forest, Scand. J. For. Res. 18 (2003) 64-77.

[12] Fridman J, Ståhl G., A three-step approach for modelling tree mortality in Swedish forests, Scand. J. For. Res. 16 (2001) 455-466.

[13] Gadow K.v., Hui G., Modelling Forest Development, Kluwer Academic Publishers, 1999.

[14] García O., Growth modelling - A (re)view, New Zealand Forestry 33 (1988) 14-17.

[15] Hamilton D.A., Brickell J.E., Modeling methods for a two-stage system with continuous responses, Can. J. For. Res. 13 (1983) $1117-1121$.

[16] Hann D.W., Development and evaluation of even-aged and uneven-aged ponderosa pine /Arizona fescue stand simulator, USDA For. Serv. Res. Pap. INT-267, 1980.

[17] Hartley H.O., The modified Gauss-Newton method for the fitting of nonlinear regression functions by least squares, Technometrics 3 (1961) 269-280.

[18] Hosmer D.W., Lemeshow S., Applied Logistic Regression, 2nd ed., Wiley, New York, 2000.

[19] Lee J.Y., Predicting mortality for even-aged stands of lodgepole pine, For. Chron. 47 (1971) 29-32.

[20] López C.A., Gorgoso J., Castedo F., Rojo A., Rodríguez R., Álvarez J.G., Sánchez F., A height-diameter model for Pinus radiata D. Don in Galicia (Northwest Spain), Ann. For. Sci. 60 (2003) 237-245.

[21] Lynch T.B., Huebschmann M.M., Murphy P.A., A survival model for individual shortleaf pine trees in even-aged natural stands, in: Proceedings of international conference on integrated resource inventories, Boise, Idaho, 1998, pp. 533-538.

[22] Lynch T.B., Gering L.R., Huebschmann M.M., Murphy P.A., A survival model for shortleaf pine trees growing in uneven-aged stands, in: Proceedings of tenth biennial Southern Silvicultural Research Conference, Shreveport, L.A., 1999, pp. 531-535.

[23] Lynch T.B., Hitch K.L., Huebschmann M.M., Murphy P.A., An individual-tree growth and yield prediction system for even-aged natural shortleaf forests, South. J. Appl. For. 23 (1999) 203-211.

[24] Matney T.G., Sullivan A.D., Compatible stand and stock tables for thinned and unthinned loblolly pine stands, For. Sci. 28 (1982) 161-171.

[25] Monserud R.A., Simulation of forest tree mortality, For. Sci. 22 (1976) 438-444.

[26] Monserud R.A., Sterba H., Modeling individual tree mortality for Austrian forest species, For. Ecol. Manage. 113 (1999) 109-123.

[27] Nagelkerke N.J.D., A note on a general definition of the coefficient of determination, Biometrika 78 (1991) 691-692.

[28] Peet R.K., Christensen N.L., Competition and tree death, Bioscience 37 (1987) 586-595.

[29] Peng C., Growth and yield models for uneven-aged stands: past, present and future, For. Ecol. Manage. 132 (2000) 259-279. 
[30] Pienaar L.V., Shiver B.D., Survival functions for site-prepared slash pine plantations in the flatwoods of Georgia and northern Florida, South. J. Appl. For. 5 (1981) 59-62.

[31] Pienaar L.V., Page H., Rheney J.W., Yield prediction for mechanically site-prepared slash pine plantations, South. J. Appl. For. 14 (1990) 104-109.

[32] Rennols K., Peace A., Flow models of mortality and yield for unthinned forest stands, Forestry 59 (1986) 47-58.

[33] Sánchez Rodríguez F., Estudio de la calidad de estación, crecimiento, producción y selvicultura de Pinus radiata D. Don en Galicia, Ph.D. thesis, Escuela Politécnica Superior de Lugo, Universidad de Santiago de Compostela, 2001.

[34] SAS Institute Inc., SAS/STAT User's Guide, version 8 edition, SAS Institute Inc., Cary, N.C., 2000

[35] Tomé M., Falcao A., Amaro A., Globulus V1.0.0: A regionalised growth model for eucalypt plantations in Portugal, in: Ortega A. Gezan S. (Eds.), Proceedings of the 5-7 September IUFRO Conference: Modelling growth of fast-grown tree species, 1997, pp. 138-145.
[36] Van Laar A., Akça A., Forest Mensuration, Cuvillier Verlag, Göttingen, 1997.

[37] Vanclay J.K., Modelling forest growth and yield. Applications to mixed tropical forests, CAB International, Wallingford, 1994.

[38] Weber L., Ek A., Droessler T., Comparison of stochastic and deterministic mortality estimation in an individual tree based stand growth model, Can. J. For. Res. 16 (1986) 1139-1141.

[39] Woollons R.C., Even-aged stand mortality estimation through a two-step regression process, For. Ecol. Manage. 105 (1998) 189-195.

[40] Yao X., Titus S., MacDonald S.E., A generalized logistic model of individual tree mortality for aspen, white spruce and lodgepole pine in Alberta mixedwood forests, Can. J. For. Res. 31 (2001) 283-291.

[41] Zunino C.A., Ferrando M.T., Modelación del crecimiento y rendimiento de plantaciones de Eucalyptus en Chile. Una primera etapa, in: Ortega A., Gezan S. (Eds.), Proceedings of the 5-7 September IUFRO Conference: Modelling growth of fast-grown tree species, 1997, pp. 155-164. 